\title{
Pengaruh Komunikasi Terhadap Kinerja Karyawan Pada PT. Indosurya Kencana Di Bekasi
}

\author{
Rr. Vemmi Kesuma Dewi \\ STAI Al Aqidah Al Hasyimiyyah, Jakarta, Indonesia \\ Email:vemmi_kesumadewi@alaqidah.ac.id
}

(Diterima: Nov 2020; Direvisi: Nov 2020; Dipublikasikan: Jan 2021)

\begin{abstract}
ABSTRAK
Penelitian ini bertujuan untuk mengetahui pengaruh komunikasi terhadap kinerja karyawan pada PT. Indosurya Kencana di Bekasi. Metode yang digunakan adalah explanatory research dengan sampel sebanyak 60 responden. Teknik analisis menggunakan analisis statistik dengan pengujian regresi, korelasi, determinasi dan uji hipotesis. Hasil penelitian ini variabel komunikasi diperoleh nilai rata-rata skor sebesar 3,717 dengan kriteria baik. Variabel kinerja karyawan diperoleh nilai ratarata skor sebesar 3,842 dengan kriteria baik. Komunikasi berpengaruh positif dan signifikan terhadap kinerja karyawan dengan nilai persamaan regresi $\mathrm{Y}=15,466+$ $0,618 \mathrm{X}$, dan nilai koefisien korelasi 0,726 atau memiliki tingkat hubungan yang kuat dengan nilai determinasi 52,8\%. Uji hipotesis diperoleh signifikansi $0,000<$ 0,05 .
\end{abstract}

Kata Kunci: Komunikasi, Kinerja Karyawan. 


\section{PENDAHULUAN}

Perkembangan era globalisasi mengharuskan para pengusaha untuk memajukan aktivitas usaha mereka. Perkembangan dunia usaha yang pesat ditandai dengan adanya pertumbuhan dan peningkatan jenis usaha baru. Berbagai perusahaan dengan skala besar maupun kecil telah berdiri kokoh dan berkembang sukses untuk memberikan pelayanan terbaik bagi masyarakat. Perusahaan itu sendiri pada dasarnya digunakan sebagai sarana orang-orang untuk berkumpul, bekerjasama secara sistematis dan terencana dalam memanfaatkan sumber daya saranaparasarana, data, dan lain sebagainya yang digunakan untuk mencapai tujuan bersama. Persaingan usaha semakin ketat, karenanya perusahaan dituntut untuk melaksanakan segala aktivitas operasional mereka dengan efektif dan efisien agar mampu mempertahankan eksistensinya Arifa (2013). Hal ini tentu saja karena perusahaan tersebut dihadapkan pada keter- batasan-keterbatasan dalam mengelola kegiatan usaha sehingga memerlukan perencanaan yang tepat dalam operasionalnya. Menurut Bayangkara (2011:11-14) ada tiga unsur pen-ting untuk mengembangkan perusahaan yaitu ekono- misasi, efisiensi dan efektifitas. Ekonomisasi berkaitan dengan ukuran input yang digunakan dalam berbagai program yang dikelola perusahaan.

Berbagai permasalahan yang dihadapi saat ini, mengharuskan perusahaan untuk mencari solusi yang cepat, tepat, dan akurat. Terutama permasalahan yang berhubungan dengan sumberdaya manusia dalam perusahaan. Tidak dapat dipungkiri, tenaga kerja merupakan urat nadi, unsur terpenting yang dibutuhkan oleh perusahaanAncaman nyata terbesar terhadap stabilitas ekonomi adalah angkatan kerja yang tidak siap untuk menghadapi tantangantantangan maupun perubahanperubahan yang terjadi di sekelilingnya (Sutrisno, 2011:1). Oleh karena itu perusahaan perlu mengupayakan terciptanya angkatan kerja yang loyal, kreatif inovatif, beorientasi ke depan, dan mampu berpikir kritis.

Pada beberapa perusahaan besar, rekrutmen tenaga kerja telah direncanakan secara tertulis beserta anggaran yang diperl- ukan. Biaya yang dikeluarkan harus sesuai dengan hasil yang diperoleh, yaitu tenaga kerja yang handal, sesuai dengan kriteria yang dibutuhkan oleh perusahaan. Selanjutnya, pihak personalia harus mampu mengelola karyawan sesuai dengan keahlian masing-masing. Penempatan yang keliru dapat menimbulkan keresahan, turunnya semangat dan kegairahan kerja, turunnya produktifitas, dan tanggung jawab karyawan Arifa (2013).

Pabrik kertas PT. Indosurya Kencana adalah salah satu penghasil kertas umumnya di Indonesia dan khususnya di Bekasi. Jenis kertas yang dihasilakan adalah kertas folio, HVS, kertas koran, kertas pembungkus coklat. Perusahaan ini merupakan perusahaan yang berorientasi pada pemaksimalan laba. Peru-sahaan ini bergerak dalam usaha pembuatan kertas. Sebagai perusahaan yang memiliki tujuan terse- but, diperlukan profesionalitas dan produk- tivitas kerja yang tinggi sehingga mampu menyediakan 
kebutuhan pasar. Dulu-nya perusahaan ini berbadan hukum Perseroan Terbatas. Hal ini menunjukkan bahwa perusahaan berupaya terus-menerus mengembangkan usaha dan memperbaiki kinerja internal perusahaan, termasuk kinerja manajemen sumberdaya manusia. Pihak manajemen diharapkan mampu bersikap lebih efektif dan efisien melalui dukungan sumberdaya manusia dalam perusahaan agar tujuan perusahaan dapat dicapai secara maksimal. Komunikasi diperlukan untuk mengetahui apakah manajemen telah bertindak secara efektif.

Beberapa kendala komunikasi pada Pabrik kertas PT. Indosurya Kencana Bekasi, berdasarkan hasil survey menunjukan bahwa komunikasi didalam perusahaan belum berjalan secara maksimal. Hal ini dikarenakan masih ada hambatan dalam penyampaian suatu informasi dari pihak manajemen kepada karyawan, salah satunya adalah pada bagian produksi. Hambatannya adalah berupa banyaknya saluran yang harus dilalui seperti informasi dari pihak manajemen kepada karyawan masih harus melalui beberapa manajer dan beberapa kepala bagian. Sehingga kemungkinan berubahnya informasi akan besar. Hal ini dapat dimaklumi sebab, setiap saluran yang ikut menyampaian informasi tersebut mempunyai ke-cenderungan untuk merubahnya sesuai dengan kepentingan pribadi. Padahal komunikasi yang lancar berkaitan sekali untuk peningkatan kinerja masing-masing karyawan melalui kepuasan kerja.Berdasarkan latar belakang di atas, maka penulis tertarik melakukan penelitian lebih lanjut dengan judul: Pengaruh Komunikasi Terhadap Kinerja Karyawan Pada PT. Indosurya Kencana di Bekasi"

\section{TINJAUAN PUSTAKA}

\section{Komunikasi}

Komunikasi merupakan salah satu bagian yang sangat penting dalam sebuah organisasi. Komunikasi dalam organisasi adalah proses penyampaian informasi, ide-ide diantara para anggota organisasi secara timbal balik dalam rangka mencapai tujuan yang ditetapkan. Komunikasi terjalin agar tercipta pemahaman yang sama antara karyawan dengan karyawan ataupun antara karyawan dengan atasan sehingga dapat bekerja sama dengan baik.

Dalam

komunikasi

hendaknya menggunakan bahasa yang mudah untuk dimengerti. Menurut Himstreet dan Baty dalam buku komunikasi bisnis Djoko Purwanto (2011:4) komunikasi adalah suatu proses pertukaran informasi antar individu melalui suatu sistem yang biasa (lazim), baik dengan symbol, sinyal-sinyal, maupun tindakan atau prilaku. Menurut Colquitt, LePine, dan Wesson (2011:422) komunikasi adalah proses dengan mana informasi dan arti atau makna di transfer dari sender kepada receiver. Sementara McShane dan Von Glinov (2010:270) komunikasi menunjukan pada proses dengan mana informasi dikirimkan dan di 
pahami diantara dua orang atau lebih. (Wibowo, 2014:241).

\section{Kinerja Karyawan}

Menurut Wibowo (2016:18) mengemukakan

"Kinerja merupakan hasil pekerjaan yang mempunyai hubungan kuat strategis organisasi, kepuasan kenosumen dan memberikan kontribusi ekonomi". Sedangkan menurut Ratundo dan Sacket (2016:76) mendefinisikan "Kinerja adalah kegiatan yang mencakup semua tindakan atau perilaku yang dikontrol oleh individu dan memberi kontribusi pada pencapaian tujuan-tujuan perusahaan". Pendapat serupa juga dikemukakan oleh Hariandja (2017:55) yang mengemukakan "Kinerja merupakan hasil kerja yang dihasilkan oleh karyawan atau karyawan atau perilaku nyata yang ditampilkan sesuai dengan perannya dalam organisasi. Mathis (2016:113) berpendapat "Kinerja adalah apa yang dilakukan atau tidak dilakukan oleh karyawan".

\section{METODE PENELITIAN}

\section{Populasi}

Populasi dalam penelitian ini berjumlah 60 responden PT. Indosurya Kencana di Bekasi.

\section{Sampel}

Teknik pengambilan sampling dalam penelitian ini adalah sampel jenuh, dimana semua anggota populasi dijadikan sebagai sampel. Dengan demikian sampel dalam penelitian ini sampel yang digunakan berjumlah 60 responden.

\section{Metode Analisis Data}

Jenis penelitian yang dipakai adalah asosiatif, dimana tujuannya adalah untuk mengetahui atau mencari keterhubungan antara variabel independen terhadap variabel dependennya. Dalam menganalisis data digunakan uji validitas, uji reliabilitas, analisis regresi linier sederhana, analisis koefisien korelasi, analisis koefisien determinasi dan pengujian hipotesis.

\section{HASIL PENELITIAN}

\section{Analisis Deskriptif}

Pada pengujian ini digunakan untuk mengetahui skor minimum dan maksimum skor tertinggi, ratting score dan standar deviasi dari masing-masing variabel. Adapun hasilnya sebagai berikut:

Tabel 1. Hasil Analisis Descriptive Statistics

Descriptive Statistics

\begin{tabular}{lr|r|r|r|r} 
& N & Minimum & Maximum & Mean & \multicolumn{1}{c}{ Std. Deviation } \\
\hline Komunikasi (X) & 60 & 29 & 47 & 37.17 & 4.223 \\
\hline Kinerja Karyawan (Y) & 60 & 31 & 47 & 38.42 & 3.590 \\
\hline Valid N (listwise) & 60 & & & & \\
\hline
\end{tabular}

Komunikasi diperoleh varians minimum sebesar 29 dan varians maximum 47 dengan ratting score sebesar 3,717 dengan standar deviasi 4,223. Skor ini termasuk pada rentang sakala 3,40
- 4,19 dengan kriteria baik atau setuju.

Kinerja karyawan diperoleh varians minimum sebesar 31 dan varians maximum 47 dengan ratting score sebesar 3,842 dengan 
standar deviasi 3,590. Skor ini termasuk pada rentang sakala 3,40 - 4,19 dengan kriteria baik atau setuju.

\section{Analisis Verifikatif}

Pada analisis ini dimaksudkan untuk mengetahui pengaruh variabel independen terhadap variabel dependen. Adapun hasil pengujian sebagai berikut: a. Analisis Regresi Linier Sederhana

Uji regresi ini dimaksudkan untuk mengetahui perubahan variabel dependen jika variabel independen mengalami perubahan. Adapun hasil pengujiannya sebagai berikut:

Tabel 2. Hasil Pengujian Regresi Linier Sederhana

Coefficients $^{\mathrm{a}}$

Unstandardized

Coefficients

Standardized

\begin{tabular}{|c|c|c|c|c|c|}
\hline \multirow[b]{2}{*}{ Model } & \multicolumn{2}{|c|}{ Coefficients } & \multirow{2}{*}{$\begin{array}{c}\text { Coefficients } \\
\text { Beta }\end{array}$} & \multirow[b]{2}{*}{$\mathrm{t}$} & \multirow[b]{2}{*}{ Sig. } \\
\hline & B & Std. Error & & & \\
\hline (Constant) & 15.466 & 2.870 & & 5.389 & .000 \\
\hline Komunikasi (X) & 618 & .077 & .726 & 8.048 & .000 \\
\hline
\end{tabular}

Berdasarkan hasil pengujian pada tabel di atas, diperoleh persamaan regresi $\mathrm{Y}=15,466+0,618 \mathrm{X}$. Dari persamaan tersebut dijelaskan sebagai berikut:
1)
Konstanta

sebesar 15,466 diartikan jika komunikasi tidak ada, maka telah terdapat nilai kinerja karyawan sebesar 15,466 point.

\section{2) Koefisien}

regresi komunikasi sebesar 0,618 , angka ini positif artinya setiap ada

Tabel 3. Hasil Pengujian Koefisien Korelasi Komunikasi Terhadap Kinerja

Karyawan

Correlations $^{\mathrm{b}}$

Komunikasi Kinerja Karyawan (X1) peningkatan komunikasi sebesar 0,618 point maka kinerja karyawan juga akan mengalami peningkatan sebesar 0,618 point

b. Analisis Koefisien Korelasi Analisis koefisien korelasi dimaksudkan untuk mengetahui tingkat kekuatan hubungan dari variabel independen terhadap variabel dependen. Adapun hasil pengujian sebagai berikut:

\begin{tabular}{llr|r} 
& \multicolumn{2}{c}{$\begin{array}{c}\text { Karyawan } \\
\text { Correlations }\end{array}$} \\
& & $\begin{array}{c}\text { Komunikasi } \\
(\mathrm{X} 1)\end{array}$ & $\begin{array}{c}\text { Kinerja Karyawan } \\
(\mathrm{Y})\end{array}$ \\
\hline Komunikasi (X) & Pearson Correlation & 1 & $.726^{* *}$ \\
\cline { 2 - 4 } & Sig. (2-tailed) & .000 \\
\hline Kinerja Karyawan (Y) & Pearson Correlation & $.726^{* *}$ & 1 \\
\cline { 2 - 4 } & Sig. (2-tailed) & .000 & .00 \\
\hline
\end{tabular}

\begin{tabular}{llr}
\multicolumn{2}{c}{ Berdasarkan } & hasil \\
pengujian & diperoleh & nilai \\
korelasi & sebesar & 0,726
\end{tabular}

artinya komunikasi memiliki hubungan yang kuat terhadap kinerja karyawan. 
c. Analisis Koefisien

Determinasi

Analisis koefisien determinasi dimaksudkan untuk mengetahui besarnya persentase pengaruh dari variabel independen terhadap variabel dependen. Adapun hasil pengujian sebagai berikut:

Tabel 4. Hasil Pengujian Koefisien Determinasi Komunikasi Terhadap

Kinerja Karyawan

Model Summary

\begin{tabular}{|c|c|c|c|c|}
\hline Model & $\mathrm{R}$ & R Square & $\begin{array}{l}\text { Adjusted R } \\
\text { Square }\end{array}$ & $\begin{array}{l}\text { Std. Error of the } \\
\text { Estimate }\end{array}$ \\
\hline 1 & $.726^{\mathrm{a}}$ & .528 & .519 & 2.489 \\
\hline
\end{tabular}

Berdasarkan hasil pengujian diperoleh nilai determinasi sebesar 0,528 artinya komunikasi memiliki kontribusi pengaruh sebesar $52,8 \%$ terhadap kinerja karyawan, sedangkan sisanya sebesar $47,2 \%$ dipengaruhi oleh faktor lain yang tidak dilakukan penelitian

Tabel 5. Hasil Uji Hipotesis Komunikasi Terhadap Kinerja Karyawan.

Coefficients $^{\mathrm{a}}$

Unstandardized

Coefficients

B Std. Error

\section{d. Uji Hipotesis}

Pengujian hipotesis dengan uji t digunakan untuk mengetahui hipotesis mana yang diterima. Rumusan hipotesis: Terdapat pengaruh yang signifikan antara komunikasi terhadap kinerja karyawan.

\begin{tabular}{|c|c|c|c|c|c|}
\hline \multirow[b]{2}{*}{ Model } & \multicolumn{2}{|c|}{ Coefficients } & \multirow{2}{*}{$\begin{array}{c}\text { Coefficients } \\
\text { Beta }\end{array}$} & \multirow[b]{2}{*}{$\mathrm{t}$} & \multirow[b]{2}{*}{ Sig. } \\
\hline & B & Std. Error & & & \\
\hline $1 \quad$ (Constant) & 15.466 & 2.870 & & 5.389 & .000 \\
\hline Komunikasi (X) & .618 & .077 & .726 & 8.048 & .000 \\
\hline
\end{tabular}

Berdasarkan hasil pengujian pada tabel di atas, diperoleh nilai $\mathrm{t}$ hitung $>\mathrm{t}$ tabel atau $(8,048>2,002)$, dengan demikian hipotesis yang diajukan bahwa terdapat pengaruh yang signifikan atara komunikasi terhadap kinerja karyawan diterima.

\section{PEMBAHASAN}

HASIL

\section{PENELITIAN}

1. Kondisi Jawaban Responden Variabel Komunikasi

Berdasarkan jawaban responden, variabel komunikasi diperoleh ratting score sebesar 3,717 berada di rentang skala 3,40 - 4,19 dengan kriteria baik atau setuju.

2. Kondisi Jawaban Responden Variabel Kinerja Karyawan

Berdasarkan jawaban responden, variabel kinerja karyawan diperoleh ratting score sebesar 3,842 berada di rentang skala 3,40 - 4,19 dengan kriteria baik atau setuju.

3. Pengaruh

Komunikasi Terhadap Kinerja Karyawan

Komunikasi berpengaruh signifikan terhadap kinerja 
karyawan dengan persamaan regresi $\mathrm{Y}=15,466+0,618 \mathrm{X}$, nilai korelasi sebesar 0,726 atau memiliki hubungan yang kuat dengan kontribusi pengaruh sebesar 52,8\%. Pengujian hipotesis diperoleh nilai t hitung > $\mathrm{t}$ tabel atau $(8,048>2,002)$. Dengan demikian hipotesis yang diajukan bahwa terdapat berpengaruh signifikan antara komunikasi terhadap kinerja karyawan diterima.

\section{KESIMPULAN DAN SARAN}

\section{A. Kesimpulan}

1. Variabel komunikasi diperoleh ratting score sebesar 3,717 berada di rentang skala 3,40 4,19 dengan kriteria baik atau setuju.

2. Variabel kinerja karyawan diperoleh ratting score sebesar 3,842 berada di rentang skala 3,40 - 4,19 dengan kriteria baik atau setuju.

3. Komunikasi berpengaruh signifikan terhadap kinerja karyawan dengan persamaan regresi $\mathrm{Y}=15,466+0,618 \mathrm{X}$, nilai korelasi sebesar 0,726 atau kuat dan kontribusi pengaruh sebesar $52,8 \%$ sedangkan sisanya sebesar $47,2 \%$ dipengaruhi faktor lain. Uji hipotesis diperoleh nilai t hitung $>$ t tabel atau $(8,048>2,002)$.

\section{B. Saran}

1. Perusahaan harus selalu membangun komunikasi yang lebih intern dan pendekatan kepada karyawan sehingga karyawan memiliki semangat dan pemberian apresiasi yang layak untuk memastikan karyawan memiliki semangat kerja yang tinggi.

2. Kinerja perusahaan dapat ditingkatkan dengan memberdayakan karyawan dengan menegakkan peraturan yang baik dan pemberian motivasi yang lebih inten lagi.

\section{DAFTAR PUSTAKA}

Abdullah, M (2014) Manajemen dan Evaluasi Kinerja Karyawan, Yogyakarta: Penerbit Aswaja Pressindo.

Akbar, I. R. (2020). Pengaruh Kompensasi Dan Etos Kerja Terhadap Komitmen Organisasi Pada Pt. Central Buana Mandiri. Value: Jurnal Manajemen dan Akuntansi, 15(1), 73-80

Algifari. (2015). Analisis Regresi untuk Bisnis dan Ekonomi. Yogyakarta: BPFE.

Arikunto, Suharsimi (2014). Prosedur Penelitian Suatu Pendekatan Praktek. Jakarta: Rineka Cipta.

Bejo Siswanto (2013) Manajemen Tenaga Kerja Rancangan dalam Pendayagunaan dan Pengembangan Unsur Tenaga Kerja, Bandung: Sinar Baru.

Dewi, R. V., Sunarsi, D., \& Akbar, I. (2020). Dampak Penggunaan Teknologi Informasi dan Komunikasi Terhadap Minat Belajar Siswa di SMK Ganesa Satria Depok. Jurnal Ilmiah Wahana Pendidikan, 6(4), 1001-1007.

https://doi.org/10.5281/zenodo. 4395889

Edi Sutrisno (2016). Manajemen Sumber Daya Manusia. Jakarta: Prenadamedia Group. 
George Terry R \& Rue, Leslie W. Rue (2016) Dasar-Dasar Manajemen, Jakarta Bumi Aksara.

Gerry Dessler (2016) Human Resources Management, Prenticehall, London: International Inc.

Handoko (2016) Manajemen Personalia dan Sumberdaya Manusia. Yogyakarta: BPFE.

Hasibuan, Malayu S.P. (2016). Manajemen Sumber Daya Manusia. Edisi Revisi. Jakarta: PT Bumi Aksara.

Imam Ghozali (2017). Aplikasi Analisis Multivariate Dengan Program SPSS. Edisi Kelima. Semarang: Badan Penerbit Undip.

Istijanto (2014) Riset Sumber Daya Manusia. Jakarta: PT. Gramedia Pustaka

Jasmani, J., \& Paeno, P. (2019). The Effect of Leadership and Competence on Lecturer Performance and Its Implications on Student Learning Motivation at Pamulang University. International Journal of Advances in Social and Economics, 1(4).

Luthans Fred (2014) Organizational Behavior, New York: McGrawHill.

Mangkunegara, Prabu Anwar. (2016). Evaluasi Kinerja SDM. Bandung: Cetakan ke tujuh, PT Refika Aditama.

Robbins, P.S, \& Judge, A.T. (2003). Organizational Behavior. Jakarta: Salemba Empat.

Rozi, A., Agustin, F., Hindriari, R., Rostikawati, D., \& Akbar, I. R. (2020). The Effect Of
Leadership On Employee Performance at PT. Stella Satindo In Jakarta. HUMANIS (Humanities, Management and Science Proceedings), 1(1).

Santoso, Singgih (2015). Menguasai

Statistik Multivariat. Jakarta: PT Elex Media Komputindo.

Sarwani, S., Akbar, I. R., Handoko, A. L., \& Ilham, D. (2020). Pengaruh Pelatihan dan Motivasi terhadap Produktivitas Kerja Karyawan pada PT. Lion Mentari Airlines Bandara Internasional Soekarno Hatta Cengkareng. Jurnal Ilmu Komputer dan Bisnis, 11(2a), 91-100.

Sedarmayanti (2016) Manajemen Sumber Daya Manusia, Reformasi Birokrasi dan Manajemen Karyawan Negeri Sipil, Cetakan Kelima, Bandung: PT Refika Aditama.

Sudjana (2014) Metode Statistika, Bandung: Tarsido.

Sugiyono (2017), Metode Penelitian Administrasi: dilengkapi dengan Metode $R \& D$. Bandung: Alfabeta.

Suhartanto (2014). Metode Riset Pemasaran. Bandung: Alfabeta Sunarsi, D. (2018). Pengaruh Gaya Kepemimpinan dan Disiplin Kerja Terhadap Kinerja Karyawan Pada CV. Usaha Mandiri Jakarta. JENIUS (Jurnal Ilmiah Manajemen Sumber Daya Manusia), 1(2).

Veithzal Rivai (2015) Manajemen Sumber Daya Manusia Untuk Perusahaan, Jakarta: Raja Grafindo Persada.

Wibowo (2015) Manajemen Kinerja, Jakarta: PT. Raja Grafindo Persada. 